\title{
FOTONARRATIVAS DE PRÁTICAS PEDAGÓGICAS: UMA ANÁLISE SOBRE AS PERCEPÇÕES DE GÊNERO NA EDUCAÇÃO INFANTIL
}

\author{
Raquel Aparecida Batista ${ }^{1}$, Bárbara Cristina Moreira Sicardi Nakayama ${ }^{2}$ \\ ${ }^{1}$ Mestre em Educação pela Universidade Federal de São Carlos - UFSCAR, Campus Sorocaba, SP. Atualmente é \\ coordenadora pedagógica, vinculada à Secretaria de Educação da Prefeitura Municipal de Hortolândia, SP. E-mail: \\ quel_baptista@hotmail.com \\ ${ }^{2}$ Pós-doutoranda em Educação pela Pontifícia Universidade Católica - PUC-SP. Doutora em Educação pela \\ Universidade Estadual de Campinas - UNICAMP. Docente da Universidade Federal de São Carlos - UFSCAR, Campus \\ Sorocaba, SP.
}

\section{RESUMO}

O presente artigo apresenta resultados parciais da pesquisa de mestrado desenvolvida no Programa de Pós-Graduação em Educação na Universidade Federal de São Carlos (UFSCar) - Campus de Sorocaba. Tendo como objeto de estudo a prática pedagógica da pesquisadora e de três professoras da Educação Infantil a pesquisa buscou responder o seguinte questionamento: Quais percepções de gênero se revelam nas práticas pedagógicas das professoras de Educação Infantil? Para responder tal questão o estudo estruturou-se dentro da perspectiva qualitativa e utilizou-se como produção de dados a construção de narrativas (oral e escrita) a partir de fotografias da prática pedagógica das docentes participantes da pesquisa. Os resultados evidenciam que as percepções de gênero das professoras pesquisadas em alguns momentos demonstram priorizar aspectos biológicos em outros aspectos sociais, no entanto existe por parte delas a intenção consciente de romper com certos modelos hegemônicos e promover práticas promotoras de equidade de gênero.

Palavras - chave: Prática pedagógica. Gênero. Infância. Educação Infantil. Fotonarrativas.

\section{PHOTO-NARRATIVES OF PEDAGOGICAL PRACTICES: AN ANALYSIS ABOUT THE PERCEPTIONS OF GENDER IN EARLY CHILDHOOD EDUCATION}

\begin{abstract}
This article presents partial results from the master's degree research developed in the Post-Graduation in Education program in Universidade Federal de São Carlos (UFSCar) - Sorocaba Campus. Having as object of study the pedagogical practice of the researcher and three teachers of early childhood education, the research seeked the answer for the following questioning: what perceptions of gender reveal themselves in the pedagogical practices of the early childhood education teachers? To answer such question, the study structured itself in the qualitative perspective and used as data production the construction of narratives (oral and written) starting from photographies of the pedagogical practices of the teachers that participated in the research. The results evidence that the perceptions about genders of the researched teachers in some moments demonstrate to prioritize biological aspects, in others, social ones, however, there is, on their part, the conscious intention to break up with some hegemonic models and to promote practices promoters of gender equity.
\end{abstract}

Keywords: Pedagogical practice. Gender. Childhood. Early Childhood Education. Photonarratives. 


\section{FOTONARRATIVAS DE PRÁCTICAS PEDAGÓGICAS: UN ANÁLISIS SOBRE LAS PERCEPCIONES DE GÉNERO EN} LA EDUCACIÓN INFANTIL

\section{RESUMEN}

El presente artículo presenta resultados parciales de la investigación de máster desarrollada en el Programa de Posgrado en Educación de la Universidad Federal de São Carlos (UFSCar) - Campus de Sorocaba. Llevando como propósito de estudio la práctica pedagógica de la investigadora y tres maestras de Educación Infantil, la investigación buscó contestar la siguiente pregunta: ¿Cuáles percepciones de género se revelan en las prácticas pedagógicas de las maestras de Educación Infantil? Para contestarla, el estudio se diseñó dentro de la perspectiva cualitativa, y se utilizó como producción de datos, la construcción de narrativas (oral y escrita) a partir de fotografías de la práctica pedagógica de los maestros agregados a la investigación. Los resultados comprueban que las percepciones de género de las maestras, investigadas en algunos momentos, demuestran dar prioridad a los aspectos biológicos en otros aspectos sociales, $\sin$ embargo, existe por parte de ellas la intención consciente de romper con ciertos modelos hegemónicos y fomenta prácticas promotoras de equidad de género.

Palabras Claves: Práctica pedagógica. Género. Niñez. Educación Infantil. Fotonarrativas.

\section{INTRODUÇÃO}

O presente artigo apresenta um recorte da dissertação de mestrado de Batista (2018) vinculada ao Núcleo de Estudos e Pesquisas sobre Narrativas, Formação e Trabalho Docente (NEPEN) desenvolvida no Programa de PósGraduação em Educação na Universidade Federal de São Carlos (UFSCar) campus de Sorocaba. A pesquisa intitulada de "Fotonarrativas $e$ percepções de professoras da Educação Infantil sobre gênero: uma análise a partir das práticas pedagógicas" traz uma a aproximação entre as temáticas práticas pedagógicas e gênero no âmbito da Educação Infantil, com intuito de fomentar o debate sobre as questões de gênero desde a infância e contribuir para a desconstrução de estereótipos que são reproduzidos através das práticas pedagógicas.

A Educação Infantil como primeira etapa da educação básica, conforme explicita a Lei de Diretrizes e Bases da Educação Nacional - LDBEN (1996) marca o primeiro convívio social mais amplo das crianças, oportunizando a convivência com diferenças não conhecidas no bojo familiar. As crianças passam a ter um espaço próprio e coletivo de educação para viver a infância, construir conhecimento, produzir cultura, devendo ser respeitadas como sujeitos históricos e de direitos em todas as dimensões, tendo a oportunidade de aprender a conviver com valores e regras estabelecidas, interagindo e participando das construções sociais.
No entanto, ao ingressar em uma instituição de educação, a criança também se insere no processo de normatização dos padrões preestabelecidos pela sociedade de maneira formal, conforme afirma Abramowicz (2003, p. 16),

[...] ao mesmo tempo em que anuncia a decidida inserção da criança na cultura, o reconhecimento de sua cidadania como um sujeito de direitos, pode vir a ser uma maneira de captura e de escolarização precoce no sentido da disciplinarização, normalização e normatização do corpo, das palavras, dos gestos, na produção de um determinado tipo de aprendiz, trazendo, portanto, uma rejeição a alteridade às diferenças que as crianças anunciam.

Tal normatização pode impedir que meninos e meninas inseridos nas instituições de Educação Infantil explorem de maneira natural e enriquecedora as diferenças existentes neste espaço. Portanto, se as instituições de Educação Infantil são espaços marcados pelas diferenças de raça, gênero, classe social e idade, podemos nós, adultos, negligenciá-las por meio de práticas pedagógicas homogeneizadoras que determinam quais os lugares para meninos e para as meninas reproduzindo preconceitos de gênero?

Moreno (1999) aponta-nos que os modelos de comportamento são transmitidos de geração em geração por meio de imitação de condutas e atitudes que não são justificadas, 
apenas compartilhadas por quase todos. No entanto, para que aconteça uma mudança nos modelos de comportamento impostos pela concepção sexista, é preciso mudança profunda na mentalidade dos indivíduos e o lugar privilegiado para que isso aconteça é a escola, pois "tem marcada uma dupla função: a formação intelectual e a formação social dos indivíduos" (MORENO, 1999, p. 17).

Perceber as instituições de Educação Infantil como lugar privilegiado para a construção de relações de igualdade é discurso comum e recorrente dos profissionais da Educação, sejam pesquisadores (as) ou professores (as). Sabe-se que tal discurso é o início para a construção de uma escola que não busca a homogeneização das crianças, mas que promove relações pautadas em respeito mútuo. No entanto, somente o discurso não é capaz de tal transformação. É preciso atentar-se às práticas dos (as) professores (as) que passam despercebidas, mas que expressam e reproduzem concepções preconceituosas tanto dentro como fora da escola.

Sendo a escola um importante espaço de desconstrução de comportamentos estereotipados, é importante trabalhar com as questões de gênero desde a Educação Infantil, buscando promover práticas educativas não discriminatórias desde a primeira infância.

Apesar de compreender que o gênero é presente nas instituições de Educação Infantil, nos modos de relacionar, nas atividades planejadas, no modo como professores (as) organizam os espaços das salas de aula é um assunto pouco discutido pelos profissionais que atuam com crianças, porém necessário, como afirma Finco (2003, p. 99-100) "discutir as relações de gênero na educação significa refletir sobre as relações das práticas educacionais cotidianas, desconstruindo e redescobrindo significados. Significa questionar conceitos préconcebidos, determinações que sutilmente permeiam nossas práticas".

Deste modo, discutir as relações de gênero na educação significa refletir sobre as práticas pedagógicas cotidianas de modo a desconstruir conceitos pré-concebidos que permeiam o trabalho com crianças e atribuir novos significados rompendo com práticas sexistas. De acordo com Scott (1995) o conceito de gênero é um elemento constitutivo das relações sociais fundadas sobre as diferenças entre os sexos como também uma forma de significar as relações de poder. É a construção social que numa dada cultura estabelece as relações de poder entre homens e mulheres.

A noção de gênero dentro desta perspectiva indica que a construção do sujeito como homem e mulher ocorre de diferentes formas nas sociedades e em determinado tempo histórico. O que significa afirmar que numa mesma sociedade as relações de gênero podem ser compreendidas de maneira diversa.

Antes mesmo de nascerem as crianças já são generificadas, diferenciadas e identificadas. Ainda no ventre materno o rosa é designado para meninas e o azul para meninos. O gênero, portanto, estabelece a forma como meninas e meninos devem comportar-se e viver suas feminilidades e masculinidades desde a infância. Assim a construção da infância muitas vezes é também a construção de um padrão de comportamento pautado na distinção dos gêneros.

Para Vianna e Finco (2009) esse processo de feminilização e masculinização dos corpos infantis que acaba por controlar os sentimentos, movimentos e desenvolvimento das crianças está relacionado às expectativas que a sociedade e cultura carrega e acaba refletindo nas brincadeiras e brinquedos que disponibilizamos para as crianças. Assim desde cedo elas vão "aprendendo" de maneira muito prazerosa e mascarada, a comportar-se como "verdadeiros" meninos e meninas (VIANNA; FINCO, 2009, p. 272).

A partir destas afirmações, justificamos a importância de pesquisar a prática de professores (as) da Educação Infantil tendo como eixo o gênero, pois para que haja superação de práticas que reproduzem preconceitos de gênero é necessário que as discussões acerca da temática sejam ampliadas. Para responder a questão que norteou o estudo: Quais percepções de gênero se revelam nas fotonarrativas das práticas pedagógicas das professoras de Educação Infantil? utilizamos as narrativas como metodologia de investigação e produção dos dados.

Segundo autores como Nóvoa (1995), Sicardi (2008) e Sicardi Nakayama (2015) o trabalho com narrativas oferece a possibilidade de ouvir a voz das professoras e fazer aproximações de sua história de vida com sua prática. Assim as narrativas, relatos de vida, relatos da prática e (auto) biografia permitem "estudar temas como a intersubjetividade, a vida cotidiana, os papéis sociais, os valores, as 
identidades, o compromisso, a troca de interesses individuais e coletivos" como afirma Sicardi (2008, p. 59). Dentro do contexto desta pesquisa, as narrativas das professoras participantes possibilitaram conhecer o modo como se constituíram mulher, profissional da educação e os valores que permeiam suas práticas.

Para discutir o gênero como uma construção social, trazemos as contribuições de Scott (1995). A discussão do gênero na Educação e na Educação Infantil está pautada em Finco (2003, 2004, 2010), Moreno (1999) e Sayão (2003).

O artigo está estruturado da seguinte maneira: no primeiro tópico apresentaremos o delineamento metodológico. Logo após, discorreremos sobre os resultados parciais e a discussão sobre as percepções de gênero das professoras e por fim, tecemos algumas considerações sobre a pesquisa.

\section{CAMINHOS PERCORRIDOS}

Este artigo como já mencionado, configura-se no recorte de uma pesquisa maior realizada no âmbito de uma pesquisa de mestrado. A opção por utilizar fotografias da prática pedagógica de professoras da Educação Infantil relacionadas à temática do gênero partiu quando nos deparamos com esta imagem:

Figura 1. O coração e o cavalo

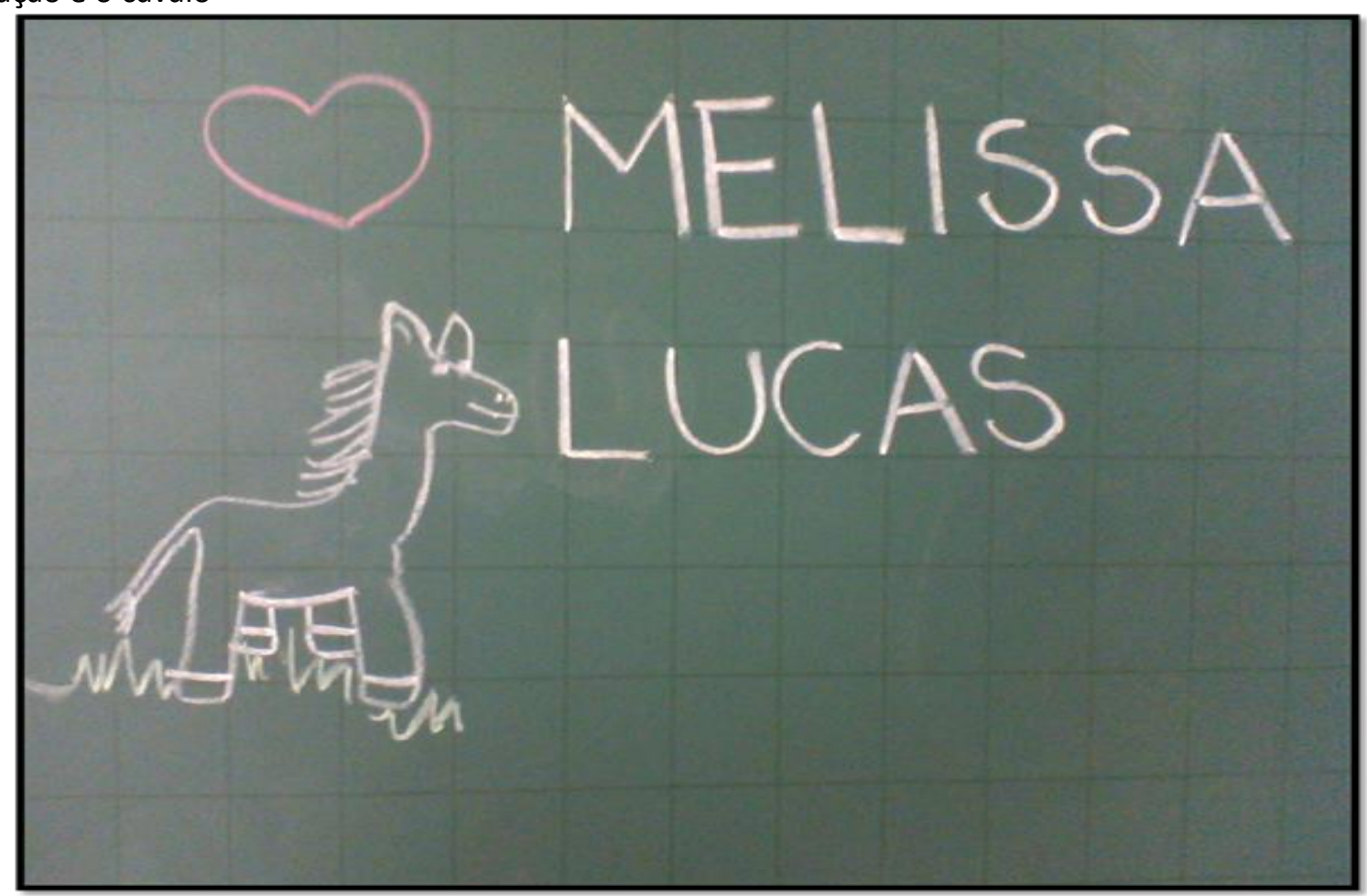

Fonte: (AUTORA, 2013)

Esta ilustração intitulada por nós de "O coração e o cavalo" feita na lousa por uma professora de crianças de quatro a cinco anos de idade para representar as crianças que seriam ajudantes do dia trouxe a tona alguns questionamentos relevantes sobre a prática pedagógica e as percepções de gênero: Qual concepção ela tem de gênero? Ela tem consciência do que de fato representou nesta imagem? Por que coração para representar a menina o e cavalo para o menino?
Assim a problemática que orientou 0 desenvolvimento da pesquisa parte do seguinte questionamento: Quais percepções de gênero se revelam nas fotonarrativas das práticas pedagógicas das professoras de Educação Infantil? Diante da problemática central da pesquisa, que consiste em responder a questão, os métodos de pesquisa qualitativa são os mais adequados e capazes de responder os questionamentos e problemáticas que surgem no decorrer do desenvolvimento da pesquisa, pois, 
de acordo com Gatti e André (2010), permitem melhor compreensão dos processos de aprendizagem, de relações dos processos institucionais e culturais.

Ludke e André (1986) afirmam que, dentro da pesquisa qualitativa, a escolha dos métodos e o modo como são coletados os dados são essenciais para o resultado da pesquisa. Assim, optamos pela narrativa (oral e escrita) a partir de registros fotográficos da prática.

Nos últimos anos, o desenvolvimento de estudos que envolvem metodologia de pesquisa sobre narrativas, autobiográficas ou não, tem sido recorrente na área da educação, sobretudo no campo de formação de professores. Esse tipo de pesquisa de acordo com Nóvoa (1995) traz o professor para o centro dos debates educativos. As pesquisas de autoras como Josso (1988, 2004, 2007), Sicardi (2008) e Sicardi Nakayama (2015) oferecem-nos um novo campo teórico metodológico para pesquisa em educação, pois encontramos nas narrativas, entrevistas e autobiografias de professores uma possibilidade de ouvir a sua voz e fazer aproximações de sua história de vida com sua prática.

Assim, as narrativas, relatos de vida, relatos da prática e (auto) biografia permitem "estudar temas como a intersubjetividade, a vida cotidiana, os papéis sociais, os valores, as identidades, o compromisso, a troca de interesses individuais e coletivos" como afirma Sicardi (2008, p. 59). Dentro do contexto desta pesquisa, as narrativas das professoras participantes possibilitaram conhecer o modo como se constituíram mulher, profissional da educação e os valores que permeiam suas práticas. Além disso, encontramos nas narrativas:

[...] uma maneira, ou uma via de conhecer o que é vivido pelas pessoas com toda a sua carga de subjetividade, partindo da estruturação dos acontecimentos que constrói a pessoa que narra a sua vida e assim poder conhecer seu contexto sócio cultural recuperando a totalidade a partir das particularidades (SICARDI, 2008, p. 60).

Por vez, o exercício de narrar expõe as nossas experiências vividas na trajetória de vida pessoal e profissional que, de modo muito particular, são articuladas às relações que estabelecemos com diferentes sujeitos, com a profissão, com as crianças, com a escola. Narramos uma trajetória marcada por escolhas, conflitos, contradições, certezas, erros e acertos, alegrias e frustrações. Desse modo, o ato de narrar permite ao professor um encontro "consigo mesmo" e que busca o desvelamento sobre "como me tornei no que sou" e "como tenho eu as ideias que tenho" (JOSSO, 1988, p. 41).

O uso da fotografia com narrativa caracteriza-se como uma fusão de elementos que apesar de distintos, completam-se. É a cumplicidade da imagem com a palavra. Os registros fotográficos da prática serão utilizados como elementos disparadores para a produção das narrativas, pois as fotografias também estão cheias de memórias, de histórias para contar e, dependendo do olhar, são capazes de trazer o visível e o invisível.

Tomamos a fotografia como um recurso tecnológico muito utilizado pelas professoras no cotidiano com as crianças, com a capacidade de "capturar", fixar e ou registrar momentos significativos da prática pedagógica e de provocar diferentes olhares, ampliando os modos de ver e compreender uma mesma imagem. Assim, o uso da imagem na pesquisa científica:

[...] pode ser pensada como forma de evidenciar os fatos e situações, a representação como forma de acesso e comprovação da realidade e a duração como forma de marcar, neste território de verdades científicas, a fugacidade da vivência e das visibilidades cotidianas (TITTONI et al., 2010, p. 60).

O contexto escolhido para produção de dados desta pesquisa foi uma instituição de Educação Infantil por dois fatores. O primeiro justifica-se pelo fato da pesquisadora estar inserida como profissional neste nível de ensino há pouco mais de oito anos. O segundo fator, fundamentado por pesquisadoras da infância e da educação para a infância como Ana Lúcia Goulart de Faria (2007) e Daniela Finco (2004, 2010) é que as instituições de Educação Infantil são espaços coletivos marcados por todos os tipos de diferenças, tornando-se ambientes privilegiados para aprender e ensinar a convivência com as diferenças, como também para problematizar como se dão essas relações e a construção desses aprendizados, tornando, assim, espaços privilegiados para pesquisa.

Convém enfatizar, também, que optamos por uma instituição de Educação Infantil no município de Campinas - SP por estar previsto no 
Plano Municipal de Educação e no Currículo da Educação Infantil a questão relacionada ao gênero. A definição da instituição se deu por ser dentre as convidadas a única a aceitar participar da pesquisa.

No primeiro contato com a equipe gestora da escola levamos a carta de apresentação e convite da pesquisa e agendamos uma conversa com todas as professoras da escola. Após a primeira visita, retomamos em uma reunião de $\operatorname{TDC}^{1}$ onde foi apresentada a proposta da pesquisa e fizemos o convite para as demais professoras da escola, onde três professoras optaram por participar da pesquisa.

Foi proposto as professoras que decidiram participar da pesquisa que cada uma separasse fotografias de atividades e momentos da prática pedagógica que fosse significativo para elas, incluindo, caso tivessem, fotografias relacionadas ao trabalho com relações de gênero. As entrevistas foram agendadas individualmente de acordo com a disponibilidade de cada professora e horário de TDI ${ }^{2}$.

A primeira conversa foi gravada e produzida a partir de um roteiro préestabelecido, dividido em dois momentos, sendo o primeiro mobilizado pelas seguintes questões:

- Quem sou eu?

- Como me constitui professora de Educação Infantil?

No segundo momento da entrevista foi proposto que as professoras falassem das fotografias, considerando os eixos prática pedagógica e gênero. Após o término da gravação das narrativas foi feita a textualização das mesmas pela pesquisadora. Com as narrativas textualizadas e impressas foi feita a validação das mesmas com as professoras participantes.

Apesar de ter um roteiro único para a produção das três narrativas cada uma teve um direcionamento diferente. Falar de si e da sua prática nem sempre é algo confortável, por esse motivo procurei aproximar-me mais das participantes, falar de mim enquanto profissional da educação para que elas não me vissem como uma "estranha".

Durante as conversas, procuramos fazer o exercício da escuta sensível e fazer intervenções apenas se necessário. Foram bons momentos de

\footnotetext{
1 Trabalho Docente Coletivo- Reunião realizada semanalmente destinada a formação docente e planejamento coletivo.

2 Trabalho Docente Individual: momento destinado ao professor para estudos, atendimento aos pais, planejamento entre outras.
}

conversa e aprendizado mútuo que não se caracterizou apenas como um relato da prática, mas um diálogo entre as teorias, valores e saberes.

\section{PERCEPÇÕES DE GÊNERO NA PRÁTICA PEDAGÓGICA}

Segundo Cunha (2009), o conceito de percepção é o estudo dentre as mais diferenciadas áreas do conhecimento, entre elas a filosofia e a psicologia. Dentro da psicologia, de acordo com Cunha e Giordan (2010, p. 1) compreende-se que a percepção "está ligada a processos cognitivos, por meio da entrada dos estímulos externos, produzindo significações que são internalizadas pelo nosso sistema psicológico, mas que ainda não constituíram uma generalização- um conceito".

Assim, a percepção se dá através dos sentidos, das experiências e das interações, porém não é um ato apenas sensitivo. A capacidade de perceber não pode se limitar ao ato de captar e ou sentir, pois perceber é "detectar, interpretar sinais que têm origem externa ao sistema nervoso central" (CUNHA, 2009, p. 28). Nessa direção, Cavalcanti (2013, p.01) afirma que a percepção está ligada "ao presente um acontecimento próximo, que você Ihe traz uma opinião e esta opinião é sua percepção do acontecido, quando digo acontecimento próximo quero dizer que um dos seus sentidos adquiriu informações para formação de opinião".

Compreendemos, a partir de então, que a percepção está relacionada ao comportamento do indivíduo, por basear-se na interpretação que o mesmo tem da realidade vivida e do significado que cada um constrói a partir desta realidade. Desse modo, não é possível separar a percepção das demais ações do pensamento, pois, como afirma Cunha (2012, p.118), "no ato de perceber estarão presentes nossos sentimentos, impressões anteriores, conceitos já conhecidos, experiências vivenciadas".

Ao percebermos elementos da realidade, - fazemos baseados nos conhecimentos adquiridos anteriormente e analisados na situação presente. Isso nos leva a compreender que o desenvolvimento do indivíduo, sua caminhada, suas experiências, 0 seu conhecimento de mundo, têm implicações diretas no modo como a percepção de determinado objeto ou situação se dá. Neste 
sentido, o gênero é o elemento que será discutido nesta análise referindo-se ao aspecto relacional entre homens e mulheres não no sentido biológico, mas no sentido das desigualdades relacionais existentes entre ambos. Portanto, o gênero é visto como uma construção social onde a cultura estabelece os papéis e comportamentos que homens e mulheres devem cumprir.

Assim, ao pensar sobre as percepções de gênero, devemos considerar que as noções de gênero são constituídas a partir das relações estabelecidas sobre as percepções sociais e as diferenças biológicas entre os sexos, mas que não se limitam a estas diferenças. Essa percepção, por sua vez, está arraigada em classificações que tornam opostos do "ser homem" e do "ser mulher".

Comumente, nestas relações de poder as mulheres costumam desempenhar o papel de submissão, sendo coadjuvantes nas ações sociais. Todavia, devemos compreender que estas relações hierárquicas são historicamente construídas e reproduzidas socialmente. A escola, pelo seu caráter normativo, é uma das instituições que reproduz este tipo de desigualdade nas relações entre meninos e meninas.

As diferenças que hierarquizam as relações estabelecidas entre homens e mulheres são frutos de uma suposta naturalização das diferenças que são reproduzidas por várias instituições responsáveis pela nossa formação como, por exemplo, a família e a escola. Dessa forma, nós reproduzimos esses (pré) conceitos como verdades naturais e os trazemos para as relações que estabelecemos.

A partir dessas discussões, compreendemos que as percepções de gênero decorrem de construções simbólicas normatizadas pelos discursos de cada sujeito, que envolvem homens e mulheres em relações de poder que os separam socialmente e definem os papéis a serem representados. Produzir com as professoras as narrativas possibilitou-nos conhecer um pouco sobre suas histórias de vida, carreira docente e como os valores e ideais influenciam em suas práticas pedagógicas, sobretudo em suas percepções de gênero. Para identificar as participantes na pesquisa foi proposto que escolhessem elementos utilizados na costura que justificassem sua escolha. Assim as apresentamos:

\section{Professora Viés}

A professora Viés é a autora desta pesquisa. Há dezesseis anos é docente na rede municipal da cidade de Hortolândia. Atualmente exerce a função de coordenadora pedagógica de uma instituição de Educação Infantil. Escolheu o Viés por ser uma tira de tecido que capaz de dar o acabamento harmonioso a qualquer peça e possuir estampas diversas.

Eu sou, uma mulher que tem enfrentado os preconceitos de raça e gênero tão presentes por uma sociedade racista e machista e que se propõe a ocupar lugares que historicamente e socialmente não são destinados a uma mulher negra.

A minha identidade não está sendo construída apenas pelas questões relacionadas à temática do gênero, mas também a questões ligadas a temática racial, afinal de contas sou preta, negra, mulher negra! Assumir-me assim, é afirmar que estou em um processo de tornar-me mulher, de empretecer, de empoderar-me.

\section{Professora Capulana}

A professora Capulana trabalha há vinte anos na Educação Infantil na rede municipal de Campinas, sendo dezenove como monitora. Escolheu o tecido chamado Capulana por um ser de origem africana e identifica-se com a cultura afro.

Eu sou uma professora que trabalho há vinte anos na Educação Infantil, é impossível falar da Capulana professora sem falar da Capulana que foi monitora por dezenove anos e tudo o que me constituí hoje enquanto professora eu aprendi na minha função de monitora de Educação Infantil.

Sou da classe trabalhadora. Isso também me traz a minha consciência da classe trabalhadora, da relação que eu tenho com as famílias da minha sala. Não posso também deixar de falar dessa professora militante e militante também da questão da infância.

\section{Professora Casadinho}

A professora Casadinho trabalha há mais de dez anos como professora de Educação Básica. Há quatro anos optou por trabalhar na creche com crianças de dois e três anos de idade e por 
compartilhar do seu trabalho com um monitor homem.

Escolheu o nome Casadinho por ser um ponto de costura bem seguido um do outro e ela gosta de coisas juntinhas e de estar perto das pessoas. Quando questionada sobre o que a define, Casadinho diz: "Eu tenho dificuldades para definir quem eu sou! Porque tenho que ser tanta coisa: tão mãe, mulher, professora, amiga, tão tudo. Acho que sou na verdade uma mistura de tudo isso".

\section{Professora Chita}

A professora Chita trabalha na rede municipal de Campinas há oito anos como professora de Educação Infantil, atualmente com crianças entre dois e três anos. Escolheu o elemento Chita por ser um tecido que marca os espaços alternativos e de resistência que costuma frequentar.

Eu sou homossexual, já sofri e sofro muito com essas questões. Por amar uma pessoa do mesmo sexo as pessoas confundem e acham que eu não gosto de ser mulher ou que eu não posso ser feminina, ou que não tenho interesse nessas coisas, nessa compreensão cultural do que é ser mulher.

Apresentaremos a seguir recortes das narrativas das professoras Viés, Capulana, Casadinho e Chita com intuito de mostrar como suas percepções de gênero revelam-se em suas práticas pedagógicas.

Ao concluir a produção das narrativas observamos pontos em comum com relação às trajetórias formativas, conflitos de início de carreira docente e concepções de infância e ao compartilhar dessas semelhanças com a professora Capulana faz a seguinte afirmação: "Pensamos do mesmo lugar, embora fazendo coisas diferentes, partimos do mesmo fundamento."

Compreendemos diante dos relatos narrados pelas professoras e pelos registros fotográficos que o fundamento citado pela professora Capulana refere-se à concepção de infância, ou seja como elas enxergam as crianças. Com a experiência de pesquisador e formador de professores Cesar Donizete Leite conclui que as práticas pedagógicas dos professores carregam consigo entre outros fatores a concepção de infância, pois "os modos de lidar com a infância refletem ou indicam modos de pensar a infância, e modos pelos quais concebemos a infância sempre produzem práticas com as crianças" (LEITE, 2011, p. 36).

Tal reconhecimento fica explícito na narrativa da professora Viés quando afirma que: "A mudança de olhar para a criança e como ela pode aprender desdobrou-se em mudanças na minha prática. O brincar passou a ter outro sentido, outro lugar no meu planejamento". Deste modo ao enxergar a criança como um sujeito ativo, produtor de cultura, com especificidades próprias e que se desenvolve nas interações com o outro e com o meio as professoras pesquisadas tomam o brincar como eixo norteador de suas práticas pedagógicas descontruindo a visão da Educação Infantil como um período preparatório para o Ensino Fundamental. Assim, elas reconhecem que o ato de brincar é importante para o desenvolvimento integral da criança.

Ao descontruir a concepção que tinha da Educação Infantil escolarizada e conteudista professora Casadinho coloca que:

Tive que entender a criança da Educação Infantil. É tão difícil se colocar no lugar delas. Então fui colocar no lugar delas e ver o que estavam precisando, o que podia fazê-los feliz naquela hora e para o futuro também, então fui voltando meu trabalho para isso. Para serem mais felizes, serem felizes nos outros anos também a passar coisas sobre como conviver de maneira saudável, se descobrir, no que gosta e não gosta. Eu sempre gostei de procurar saber o que a criança gosta. (Professora Casadinho).

A professora Chita coloca que o brincar também é uma escolha que revela o fazer pedagógico do professor quando traz a seguinte afirmação:

Quando a gente escolhe trabalhar com o brincar e divide este brincar em várias opções, o meu trabalho de pedagoga aparece nesta escolha, aparece nesta concepção de usar o espaço ao meu favor junto comigo, aparece a importância que eu dou para o brincar e nessa mediação que eu fico fazendo ali o tempo todo. (Professora Chita). 
O trabalho com cantos diversificados é comum nas práticas das professoras Viés, Capulana, Casadinho e Chita. O modo como elas organizavam os espaços das salas planejavam as atividades, escolhiam os brinquedos e faziam as intervenções nessa dinâmica de trabalho revelam suas percepções de gênero. Como mostram os excertos abaixo:

Eu organizo os brinquedos para que todos brinquem do que quiserem, brinquem de fantasia e não com brincadeiras de meninos e de meninas separadamente. Embora tenha uma questão cultural das meninas brincarem sempre de bonecas eu procuro oferecer outras possibilidades. (Professora Capulana).

[...] A gente faz vários cantinhos na sala, quatro ou cinco para que as crianças tenham ainda que restrita elas possam ter opções e escolher. Mesmo que os cantinhos sejam montados pela gente, elas ainda podem escolher onde querem brincar. Um dos cantinhos que colocamos bastante é o de bonecas, brincar de boneca. A gente põe fraldas, bacia, banheirinha para dar banho, pente, secador, para cuidar né. Mamadeira, essas coisas.

A gente monta os cantinhos, chama as crianças, elas vem em grupos e sentam juntas em um lugar da sala da sala, explica quais cantinhos tem, fala e coloco algumas regras e perguntamos quem quer ir para os cantinhos e vamos organizando. Quando tem algum mais concorrido ai tentamos negociar. Nunca dividimos assim: meninos nos de carrinho e meninas de boneca. A gente pergunta quem quer fazer o que e onde. (Professora Chita).

Nos cantinhos cada um pode ser o que quiser e brincar do que quiser.

Temos o cantinho da leitura, da casinha, das ferramentas. Nos outros dias vou oferecendo coisas diferentes: cantinho da costura, de cabelereiro, de escritório, mas no outro dia já troco. Partindo dai vi algumas crenças das famílias mesmo. A criança vinha e pedia o carrinho, então eu perguntava, porque o carrinho? A criança respondia: _ Eu gosto do carrinho tia! Então tá bom. Então vamos ver se você vai gostar de outra coisa. Então eu abro o armário e mostro. (Professora Casadinho).
Ainda que culturalmente existam brinquedos que são estipulados para meninos e para meninas e na escola as crianças façam essas mesmas escolhas, pois já trazem para a escola concepções sobre masculinidades e feminilidades as professoras buscam oferecer outras possibilidades de brinquedos e brincadeiras. 0 modo como as professoras participantes da pesquisa fazem as intervenções e organizam as brincadeiras contribui para a promoção da formação da autonomia ao articularem momentos de interação entre as crianças sem limitar os espaços vão proporcionando igualdade de gênero através das brincadeiras. Acabam por desconstruir a relação separada das crianças entre meninos e meninas e ensinando a elas que meninos e meninas tem os mesmos direitos e deveres.

Finco (2010) alerta que é preciso ter uma intencionalidade educativa ao organizar as brincadeiras já que elas podem ser estratégias sutis de produção de relações desiguais de gênero. Porém, permitir que meninos brinquem de bonecas e meninas de carrinho não garante a promoção de uma educação não sexista como afirma Sayão (2003, p. 84):

Não basta dizer para as crianças que é possível que meninos brinquem de boneca e meninas de carrinho; com isto estaremos oportunizando relações mais solidárias ou menos hierárquicas quanto ao gênero, o que é importante, mas ainda é pouco. É preciso entender o universo de significações materiais e simbólicas que representam o "isto e o aquilo", estar "aqui e lá".

Outro tipo de separação comum nas instituições de Educação Infantil, porém não presentes nas práticas das pesquisadas refere-se a questão da fila. Capulana afirma não fazer fila de menino ou de menina, porque na vida social isso não acontece, ressalta que "A fila do banco é mista". Neste sentindo observamos a superação de uma prática comum busca romper com a diferenciação entre o feminino e masculino.

Ainda que exista o trabalho voltado para descontruir o padrão normativo de masculinidade e feminilidade existe algumas concepções a serem superadas com relação a definição de comportamentos estereotipados como ressalta a fala da professora Casadinho

A gente sabe que uma sala com mais meninos é uma sala mais ativa, mais 
agitada, mais barulhenta e uma sala com mais meninas é mais silenciosa, tem conversa, mas é mais calma. Mas por que isso? Por que queremos acostumar as meninas a serem retraídas. Senta como menina. Como é sentar como menina? E retraída. Você é uma menina não pode falar desse jeito? Ela sempre tem que falar baixo, tem sempre que ser quieta, muda? Porque ela não pode ser tão ativa como os meninos? (Professora Casadinho).

Dentro deste contexto cabe ressaltar que a maneira como meninos e meninas se comportam não são determinados pela biologia, mas sim por influência que a sociedade exerce sobre cada indivíduo sendo que a educação é um dos meios que influencia o comportamento como complementa Moreno (1999, p. 29):

Se os seres humanos se comportassem unicamente a partir de seus impulsos biológicos, se as condutas consideradas masculinas e femininas fossem espontâneas, naturais e predeterminadas, não seria necessário educar tão cuidadosamente todos os aspectos diferenciais; bastaria deixar que a natureza atuasse por si mesma.

Assim compreendemos que as manifestações espontâneas agressiva dos meninos e o caráter pacífico das meninas é resultado de um modelo que é imposto.

Nos primeiros meses de vida é impossível detectar um nível de agressividade maior nos meninos que as meninas, mas à medida que crescem, a diferença vai se acentuando. Devemos, pois concluir que a agressividade é uma das características do modelo que se apresentam para meninos e que tal característica não figura no que é apresentado às meninas. (Ibidem., $p$. 33).

Nessa direção Whitaker ${ }^{3}$ (1988 apud Finco 2004) afirma que crianças de ambos os sexos são igualmente agressivas, mas só aos meninos é permitida a expressão agressiva e, mesmo que não queiram são estimulados à

\footnotetext{
${ }^{3}$ WHITAKER, Dulce Mulher \& Homem: o mito da desigualdade, São Paulo: Ed. Moderna, 1988.
}

agressividade para seguir 0 padrão de comportamento masculino.

Lidar com as questões de gênero na prática configura-se em um desafio complexo para nós professoras e professores, pois existe a difícil tarefa de desconstruir o que é normatizado e tido como natural, trabalhar com a aceitação das famílias, e dos demais integrantes da equipe escolar que nem sempre compartilham das mesmas ideias.

A concepção de infância das professoras permitiu que elas buscassem pensar nas necessidades das crianças e em seus anseios. Isso nos revelou que as práticas não estão cristalizadas em concepções que as distanciam da possibilidade de inovações, de rupturas e de mudanças, de modo que práticas sexistas foram dando lugar a práticas promotoras de igualdade de gênero. Contudo, podemos inferir que as percepções sobre de gênero das professoras pesquisadas em alguns momentos demonstram priorizar aspectos biológicos, em outros aspectos sociais. No entanto as práticas pedagógicas revelam que mesmo inseridas em um padrão hegemônico e binário existe por parte das professoras intenção consciente de romper com certos modelos hegemônicos, com os medos, os preconceitos e promover práticas que demonstram equidade de gênero.

Ao apresentamos os fragmentos das práticas pedagógicas das professoras Viés, Capulana, Casadinho e Chita deparamo-nos com diferentes relações como: a própria concepção de prática pedagógica, educação, escola, criança, cuidar - educar, teoria e de gênero. São essas concepções que determinam as escolhas e tomadas de decisão de cada profissional e que também direcionam suas práticas.

\section{ALGUMAS CONSIDERAÇÕES}

Uma pesquisa sobre a prática pedagógica dentro da abordagem qualitativa, especialmente que discute a temática do gênero, exige do pesquisador conhecimento acerca das subjetividades, da singularidade do sujeito, ou melhor, compreender o modo como cada sujeito narra seu processo de formação pessoal e profissional. Exigiu da pesquisadora perspicácia e atenção redobrada para olhar além do que foi dito. Foi preciso chegar mais próximo das participantes para compreender a pessoa profissional, o que se passou no decorrer da vida de cada um enquanto uma pessoa social e ver o envolvimento relacional desse sujeito com o eu, o 
outro e o mundo. Neste sentido, a opção pelas narrativas para produzir os dados trouxe essa aproximação entre as professoras pesquisadas e pesquisadora.

Assim, ouvir as professoras narrarem sobre suas trajetórias docentes, processo de formação inicial e continuada e suas práticas referentes às questões de gênero causaram-nos, a princípio, certo estranhamento pelo fato de também compartilharem das mesmas dúvidas e enfrentamentos, como afirma Ávila (2002, p.40) "mas, ao mesmo tempo, sou uma igual, porque sou também uma professora que investiga as práticas das professoras". Reconhecer-me na condição de igual contribuiu para que estabelecêssemos um vínculo de confiança e as trocas de experiências caracterizaram-se em "uma interação que dá lugar a uma série de mediações entre investigador e narrador, aspecto este, que torna possível que quem investiga seja também investigado" (SICARDI, 2008, p. 65). Foram momentos altamente formativos!

Acreditamos que a reflexão crítica sobre a prática pedagógica questionando o que é "normal" convencional e rotineiro pode dar origem a um "novo jeito" de olhar para as crianças e para as relações de gênero. Esta pesquisa traz consigo este desafio: o de construir um novo olhar sobre as relações de gênero na Educação Infantil sob a ótica da criança que não vem carregada de preconceitos, e sim com a ousadia de transgredir os padrões estabelecidos.

A falta de discussão sobre este assunto nos cursos de formação, ou até mesmo na escola, não permite que os professores tenham uma visão crítica e contestem os padrões muitas vezes naturalizados na nossa sociedade, como "coisa de menina" e "coisa de menino". O resultado disso é a repetição nas atividades desenvolvidas com as crianças, como: coração para representar as meninas e cavalo para representar os meninos, panelinha para as meninas, carrinho para os meninos.

A formação de professores e professoras à luz das relações de gênero é parte do caminho que devemos trilhar para construirmos uma escola que respeite as diferentes formas de ser menino e menina. Cabe ressaltar que tal tarefa se faz cotidianamente, ao questionarmos o porquê de não oferecermos carrinhos às meninas ou bonecas aos meninos? Por que acreditamos que meninos são mais agressivos que meninas? As respostas a estas perguntas apontam caminhos para a construção da igualdade, caminhos que passam pela revisão das relações de gênero e da sexualidade na escola.

As considerações aqui apresentadas não esgotam as possibilidades de outras dimensões, tampouco encerram as reflexões e inquietações acerca da questão problematizadora que permeou essa investigação. Pelo contrário, oportuniza ampliar as possibilidades de diálogo sobre a importância de pensar em práticas pedagógicas que promovam a igualdade de gênero desde a Educação Infantil.

\section{REFERÊNCIAS}

ABRAMOWICZ, A. O direito das crianças à Educação Infantil. Pró-posições. Campinas: v.14, n.3, p. 13-24, set/dez. 2003.

AVILA, Maria Jose Figueiredo. As professoras de crianças pequenininhas e o cuidar e educar: um estudo sobre as práticas educativas em um CEMEI de Campinas/SP. 2002. 305f. Dissertação (Mestrado em Educação), Faculdade de Educação, Universidade Estadual de Campinas, Campinas,2002.

BATISTA, R.A. Fotonarrativas e percepções de professoras da Educação Infantil sobre gênero: uma análise a partir das práticas pedagógicas. 2018. Dissertação (Mestrado em Educação), Programa de Pós Graduação em Educação, Universidade Federal De São Carlos, Campus Sorocaba, 2018.

BRASIL. LDB. Lei de Diretrizes e Bases da Educação Nacional. Lei no 9394 de 20/12/1996. Brasília, 1996.

CAVALCANTI, Thiago. Percepção, Concepção e Comportamento Individual. Grupo de Estudos Gestão Total. 2013. Disponível em: http://grupodeestudosgt.blogspot.com.br/2013/ 06/percepcao-concepcao-ecomportamento.html-comportamento.html acesso em: 09 set. 2017.

CUNHA, Marcia Borin da. A percepção de ciência e tecnologia dos estudantes do ensino médio e a divulgação científica. 2009. 363 f. Tese (Doutorado em Educação) - Faculdade de Educação, Universidade de São Paulo, São Paulo, 2009. 
CUNHA, Márcia Borin da; GIORDAN, Marcelo. Pesquisas de Percepções e concepções de Ciência e a necessidade de um referencial teórico IN: REUNIÃO ANUAL DA SOCIEDADE BRASILEIRA DE QUÍMICA. 33., 2010, Águas de Lindóia, 33. Anais... São Paulo: SBQ, 2010. https://doi.org/10.1590/S0100$\underline{40422010000400001}$

CUNHA, Márcia Borin da. As Percepções na Teoria Sociocultural de Vigotski: uma análise na escola. Alexandria Revista de Educação em Ciência e Tecnologia, v.5, n.1, p.113-125, mai. 2012. Disponível em: https://periodicos.ufsc.br/index.php/alexandria/ article/viewFile/37700/28870. Acesso em: 01 set. 2017.

FARIA, A. L. G. (Orgs). O Coletivo infantil em creches e pré- escolas: falares e saberes. São Paulo: Cortez, 2007.

FINCO, D. Relações de gênero nas brincadeiras de meninos e meninas na educação infantil. Pro Posições, Campinas SP, v.14, n.3, 89-101, 2003.

FINCO, D. Faca sem ponta, galinha sem pé, homem com homem, mulher com mulher: relações de gênero nas relações de meninos e meninas na pré-escola. 2004. 184 f. Dissertação (Mestrado em Educação) Faculdade de Educação da UNICAMP, 2004.

FINCO, D. Educação Infantil Espaços de confronto e convívio com as diferenças: análise das interações entre professoras e meninos e meninas que transgridem as fronteiras do gênero.2010. 198f. Tese (Doutorado em Educação). Faculdade de Educação, Universidade de São Paulo, São Paulo, 2010.

GATTI, Bernadete; ANDRÉ Marli. A relevância dos métodos de pesquisa qualitativa em Educação no Brasil. In WELLER, Wivian; PFAFF, Nicole (orgs). Metodologias da pesquisa qualitativa em Educação. Petrópolis RJ: Vozes, 2010. P. 29-38.

JOSSO, M. C. Da formação do sujeito... ao sujeito da formação. In NÓVOA, A.; FINGER, M. (orgs). 0 método (auto) biográfico e a formação. Portugal/Lisboa: Pentaedro, Tradução: Maria Nóvoa, Centro de Formação e Aperfeiçoamento Profissional, 1988, p. 35-50.
JOSSO, M. C. Experiências de vida e formação. São Paulo: Cortez, 2004.

JOSSO, M. C. A transformação de si a partir da narração de histórias de vida. Educação, Porto Alegre/RS, n. 3 (63), p. 413-438, set./dez. 2007.

LEITE, César Donizete Pereira. Infância, experiência e tempo. São Paulo: Cultura Acadêmica, 2011.

LUDKE, M.; ANDRE, M. E. D. A. Pesquisa em Educação: abordagens qualitativas. São Paulo: EPU, 1986.

MORENO, M. Como se ensina a ser menina, o sexismo na escola. Campinas: Ed. Moderna, 1999.

NÓVOA, A. (Orgs). Vida de Professores. Porto, Portugal. Ed. Porto, 1995.

SAYÃO, D. T. Pequenos homens, pequenas mulheres? Meninos e meninas? Algumas questões para pensar as relações de gênero na infância. Pró-posições. Campinas: v.14, n.3, p. 6787, set/dez.2003.

SCOTT. J. Gênero uma categoria útil para análise histórica $1995 . \quad$ Disponível em: http://wesleycarvalho.com.br/wpcontent/uploads/G\%C3\%AAnero-Joan-Scott.pdf. Acesso em: 10 de ago. de 2012.

SICARDI, B. C. M. Biografias educativas e o processo de constituição profissional de formadores de professores de matemática. Campinas, SP, 2008. 158 f. Tese (Doutorado em Educação) - Universidade Estadual de Campinas, Faculdade de Educação. UNICAMP, 2008. https://doi.org/10.15603/19828993/ml.v1n2p137-153

SICARDI NAKAYAMA, B. C. M. Leitura e produção do conhecimento e a potencialidade heurística das narrativas educativas. In: NUNES, C. M. F.; ARAUJO, R. M. B. de. (orgs.) Narrativas de Professores em Formação: O Significado de ser Pedagogo. Jundiaí, Paco Editorial: 2015.

TITTONI, J.; OLIVEIRA, R. G. de; SILVA, P. M. da; TANIKADO, G. A Fotografia na Pesquisa Acadêmica: sobre visibilidades e possibilidades de conhecer. Informática na Educação: teoria \& prática, Porto Alegre, v. 13, n. 1, p. 59-66, 
jan./jun. 2010. Disponível em:

https://doi.org/10.22456/1982-1654.10467

Acesso em: 08 mai. 2019.

VIANNA, C.; FINCO, D. Meninos e meninas na

Educação Infantil: uma questão de poder.

Disponível em:

http://www.scielo.br/pdf/cpa/n33/10.pdf.

Acesso em: 01 dez. 2017. 